\title{
Masculino plural e comunicação publicitária: A dinâmica atualização da masculinidade hegemônica*
}

\section{Filipe Bordinhão dos Santos}

Professor do Curso de Publicidade e Propaganda da Universidade Positivo. Doutorando e Mestre em Comunicação pela Universidade Federal de Santa Maria. Membro do Grupo de Pesquisa Usos Sociais da Mídia. Professor do Curso de Publicidade e Propaganda da Universidade Positivo.

E-mail: filipebordinhao@hotmail.com.

\section{Danilo Postinguel}

Mestre em Comunicação e Práticas de Consumo PPGCOM-ESPM-SP, vinculado ao Grupo de Pesquisa JUVENÁLIA Culturas juvenis: comunicação, imagem, política e consumo. Professor dos cursos de Comunicação Social do FIAMFAAM Centro Universitário.

E-mail: d.postinguel@gmail.com

\footnotetext{
* Versão ampliada de artigo apresentado e publicado nos anais do 50 Congresso Internacional em Comunicação e Consumo, na Escola Superior de Propaganda e Marketing, São Paulo, de 5 a 7 de outubro de 2015.
}

Resumo: A partir da pluralidade de representações imagéticas masculinas contemporaneamente na comunicação publicitária, problematizamos a emersão, no plano massivo, de masculinidades marginalizadas e a harmonização com a imagem de masculino, ainda hoje circulante no discurso publicitário (hegemônico). Para isso, nos valemos de bibliografias que discutem o processo de constituição de masculinidades e do papel da publicidade, articulada com as demandas da sociedade, para assim atualizar e repensar alguns valores cristalizados no contexto sociocultural. Os anúncios coletados para esse estudo sinalizam para a necessidade da publicidade criar espaços imagéticos de sociabilidade dessas representações, como também, aumentar a sua circulação. Afinal, partimos da proposta de sermos indivíduos que nos constituímos e entendemos a nossa realidade por meio das imagens.

Palavras-chave: Comunicação publicitária; Imagem; Masculinidade; Representação.

Male plural and advertising communication: The hegemonic masculinity dynamic update

Abstract: Based on the plurality of representations masculine imagery in advertising communication contemporarily, investigated the emergence, in the massive plan of marginalized masculinities and harmonization with the male image, still circulating in advertising discourse (hegemonic). For this, we make use of bibliographies discussing masculinity formation process and the role of advertising, combined with the demands of society, so as to update and rethink some values crystallized in the sociocultural context. Ads collected for this study point to the need of advertising imagery to create spaces of sociability of these representations, but also increase your circulation. After all, we start from the proposal to be individuals who constitute ourselves and understand our reality through the images.

Keywords: Advertising communication; Image; Masculinity; Representation. 


\section{Masculinidades apresentadas}

Os anúncios publicitários são estruturados por dizeres (verbais e visuais), que não só fundamentam os atributos do produto ou serviço divulgado, mas também, "deixam à mostra representações sociais e certos investimentos no imaginário coletivo" (CARRASCOZA, 2012: 1). Valendo-se desse arranjo midiático, algumas marcas e mercadorias destinadas ao público masculino estão estruturando seus dizeres para apresentar aquilo comumente intitulando como "um produto para o novo homem". Essa estratégia discursiva-imagética em torno do "novo homem" vem, na maioria das vezes, apresentar um produto até então pouco habitual do consumo masculino. Destarte, tomamos como eixo norteador, para esta pesquisa teórica, às proposições de Connell (1995), mesmo que concebidas há vinte anos, suas teorizações se mostram efervescentes ainda hoje para debater, teorizar e compreender a masculinidade e suas reverberações midiáticas.

Connell (1995: 195), ao tratar das políticas da masculinidade, afirma existir "uma agenda da masculinidade [...] que tem ganhado força com a globalização e as reivindicações políticas para obter 'competitividade internacional'", encabeçado pelo implacável empreendedor capitalista. Abordar a lógica capitalista se mostrou oportuna, pois em busca dessa competitividade internacional é agenciada concomitantemente uma "promoção comercial de masculinidades exemplares" (CONNELL, 1995: 195), promovida pela indústria cultural e averiguada por nós, por meio da comunicação publicitária.

Sendo assim, trazemos para a discussão o recorte em torno da comunicação publicitária, pois outras produções culturais midiáticas, como o cinema e a telenovela, por mais que dialoguem com vestígios sociais e culturais dentro de uma relação espaço-temporal, explicitam para as suas audiências, se tratar de narrativas ficcionais. Ressaltamos também que a publicidade se trata de uma narrativa "onipresente e (in)eficiente, talvez desviada para o (ir)real, (in)útil, [concentrando] possibilidades mas escapa às certezas" (PIEDRAS, 2008: 1). Mesmo assim, ela encontra-se mais sinérgica com o mundo real, já que, ofertam em suas retóricas, mercadorias circulantes nos mais pluralizados contextos, logo, a publicidade está disponível para todo e qualquer indivíduo, como sugerem, Santos e Ronsini (2012). Tal realidade ganha maior proporção no cenário contemporâneo, no qual a publicidade passa a fazer parte de nossas vidas de uma forma jamais vista igual, são diversos formatos espalhados nos mais inusitados espaços.

Implicando, dessa forma que, antes mesmo de se consumir a mercadoria, segundo Rocha (1995), consumimos seu anúncio. Tal realidade ganha maior proporção no cenário contemporâneo, no qual a publicidade passa a fazer parte de nossas vidas de uma forma jamais vista igual, são diversos formatos espalhados nos mais inusitados espaços. Nesse sentido, Casaqui (2011) sugere o que entende como o fenômeno da publicização, visto que

[...] diferentemente da telenovela ou do telejornalismo, que possuem espaços e horários de veiculação determinados na programação, conhecidos previamente pelos receptores (o que sugere uma ritualidade no consumo dos produtos midiáticos), a publicidade está pulverizada dentro e fora dos intervalos comerciais (SANTOS, 2014: 81).

Outro fator preponderante ao problematizar as masculinidades midiáticas por meio da publicidade é compreender tal fenômeno, além de meras "abordagens restritas ao viés do marketing e da psicologia" (SANTOS, 2014: 73), afinal, precisamos compreender que ela, "ultrapassa as questões essencialmente econômicas e se insere num contexto cultural e dialógico, isto é, encontra-se 
numa ininterrupta interação com os mais diversos campos sociais" (SANTOS e RONSINI, 2012: 2). Portanto, analisar as masculinidades circulantes nos anúncios publicitários requer compreender também sua movimentação no campo social, isto é, os sujeitos e as práticas culturais que pautam e dão sentido ao discurso por eles apresentados.

Ao passo que, ao articularmos uma visão analítica entre os agenciamentos das masculinidades e o consumo de anúncios publicitários, permitirá não só apresentar e mapear as masculinidades tidas como exemplares, hegemônicas e as outras, tidas como marginalizadas (CONNELL, 1995; CONNELL e MESSERCHMIDT, 2013), mas também problematizá-las, pensar nas suas produções e a harmonização quanto à circulação de todas essas masculinidades no mesmo contexto social. Nessa dicotomia entre a hegemônica e as marginais, Connell (1995: 189) nos lembra que, "diferentes masculinidades são produzidas no mesmo contexto social", o que já colocaria em xeque a ideia contemporânea e midiática acerca de um "novo homem". E acrescenta, "uma determinada forma hegemônica de masculinidade tem outras masculinidades agrupadas em torno dela" (CONNELL, 1995: 189).

Santos, corrobora, ao enfatizar que, não se trata de uma forma masculina que abandona todas as suas características tradicionais, portanto, trata-se "muito mais a uma atualização neste padrão tradicional, que vigorou por tanto tempo, do que exatamente ao seu desaparecimento total" (SANTOS, 2012: 41). É o caso, por exemplo, da publicidade e das promoções de marketing que, a partir de meados dos anos de 1980, começam a representar um "novo homem", tendo em vista as diversas transformações sociais e culturais, fazendo com que muitos indivíduos incorporassem tais representações as suas identidades de gênero (WOODWARD, 2009). Prosseguindo, se faz necessário e oportuno, definir, até mesmo como problematiza Connell (1995), o que entendemos por masculinidade.

\begin{abstract}
A masculinidade é uma configuração de prática em torno da posição dos homens na estrutura das relações de gênero. Existe, normalmente, mais de uma configuração desse tipo em qualquer ordem de gênero de uma sociedade. Em reconhecimento desse fato, tem-se tornado comum falar de "masculinidades". Existe o perigo, nesse uso, de que possamos pensar no gênero simplesmente como um pout-pourri de identidades e estilos de vida relacionados ao consumo. Por isso, é importante sempre lembrar as relações de poder que estão aí envolvidas (CONNELL, 1995: 188).
\end{abstract}

Quanto à crítica levantada pelo autor em torno das mobilizações identitárias articuladas ao consumo, é por meio dele que vemos hoje na comunicação publicitária a circulação dessas masculinidades mais pluralizadas. Afinal, asseveramos, mediante Rocha (2012: 22) que, "coaduna-se a interpretação do consumo como fato da cultura, esta que, cada vez mais, é permeada por fatos de imagem". Trazer o consumo para a esfera da cultura é possibilitar dar voz para demandas da sociedade que busca, por exemplo, forma mais pluralizadas de circulação e consumo de imagens masculinas. Afinal "consumir, hoje, é consumir cultura midiaticamente mediada, digitalmente interligada, imaginariamente compartilhada, imageticamente realizada" (ROCHA, 2009: 269).

A definição de masculinidade hegemônica, gestada entre as décadas de 1980 e 1990, foi baseada nos estudos gramscianos acerca da hegemonia. Conforme apontam Connell e Messerschmidt (2013), por não ter um foco claro acerca da mudança histórica, o conceito de hegemonia teria sido reduzido a um simples modelo de controle social. "E, em boa parte do debate sobre gênero, a mudança histórica em larga escala não está em foco" (CONNELL e MESSERSCHMIDT, 2013: 
243), o que, para autores, dificulta o processo de atualização desse modelo de masculinidade hegemônica, pois ela

se distinguiu de outras masculinidades, especialmente das masculinidades subordinadas. A masculinidade hegemônica não se assumiu normal num sentido estatístico; apenas uma minoria dos homens talvez a adote. Mas certamente ela é normativa. Ela incorpora a forma mais honrada de ser um homem, ela exige que todos os outros homens se posicionem em relação a ela e legitima ideologicamente a subordinação global das mulheres aos homens (CONNELL e MESSERSCHMIDT, 2013: 245).

Esse modelo hegemônico (CONNELL, 1995) e normativo (CONNELL e MESSERSCHMIDT, 2013) começou a ser concebido e lapidado com o advento da modernidade. A demarcação da relação de poder que começará a emergir com a masculinidade, pode ser localizada, como salientou Oliveira (2004), na própria concepção da modernidade, que patenteou a masculinidade como símbolo referencial desse período. E logo, tornou-se um modelo (representação) ideal a ser seguido. Assim, era e ainda é contemporaneamente considerado "um homem normal" (NOLASCO, 1993: 52), do ponto de vista do aceite e reconhecimento social, aquele que ancora sua construção identitária em uma representação masculina hegemônica/normativa. Tratando de um homem heterossexual, branco, ocidental (RIBEIRO e SIQUEIRA, 2005; NOLASCO, 1993).

Neste percurso, Hoff (2008: 170) localiza que, durante quase todo o século XX houve o que chamou de uma "pedagogização do consumo", ancorado no público feminino - obliterado ao homem - e permeada pela publicidade, concebendo a mulher o papel de assimiladora e disseminadora das práticas de consumo. Com relação à realidade brasileira, toda comunicação publicitária da época era dirigida para esse público ensinando-as o que, como e por que consumir.

Com relação à circulação da imagem masculina na publicidade, Hoff (2008) sinaliza que, a partir da década de 1920 (período inicial de sua pesquisa) a predominância de representação corpórea foi a feminina, seguindo os padrões estéticos europeus. Até 1960, ainda, era majoritária as representações femininas na publicidade, contudo, começava a circular, nesse período, mesmo que em menor quantidade, representações infantis e masculinas. Essas representações corporais masculinas "sofre[ra]m o mesmo enquadramento social dos femininos: predominam o marido ou o pai provedor em cenas com a família ou no trabalho" (HOFF, 2008: 176). Mesmo não restringindo a concepção de masculinidades ao plano dos estudos do corpo, inseri-lo neste debate é detectar indícios dessas masculinidades circulantes na cena midiática.

No entanto, ainda na década de 1960, com o surgimento dos grupos feministas organizados, lutando pela igualdade de gênero, assim como, por políticas que assegurassem à proteção das mulheres no espaço público, mais o movimento homossexual, posteriormente, propiciaram levantar alguns "questionamento[s] sobre o papel social do homem, produzindo efeitos sobre a reformulação do ideal masculino" (SANTOS, 2012: 122). Consequentemente, essa reformulação propiciou a circulação, inclusive midiática, de outras formas de masculinidades agrupadas à masculinidade hegemônica. Postinguel (2015), ao tomar como corpus a publicidade da marca de cuecas Zorba, entre as décadas de 1960 e 2010, apresenta vestígios dessas outras masculinidades, que circulam, demonstram e confrontam a masculinidade hegemônica.

Na Figura 1 (anúncio do lado direito), podemos ver essa representação social de masculinidade hegemônica também tornada midiática, circulante até a década de 1990 (HOFF, 2008). Mas, nesse período, é possível contemplar, fruto de algumas movimentações sociais e políticas, a inserção dessas outras 
masculinidades (lado esquerdo), antecipando, mesmo que de forma tímida e implícita, aquelas representações que pesquisadores contemporâneos a nós afirmaram começar a circular na década de 2000, com corpos masculinos "desnudo em poses sensuais" (HOFF, 2008: 180).
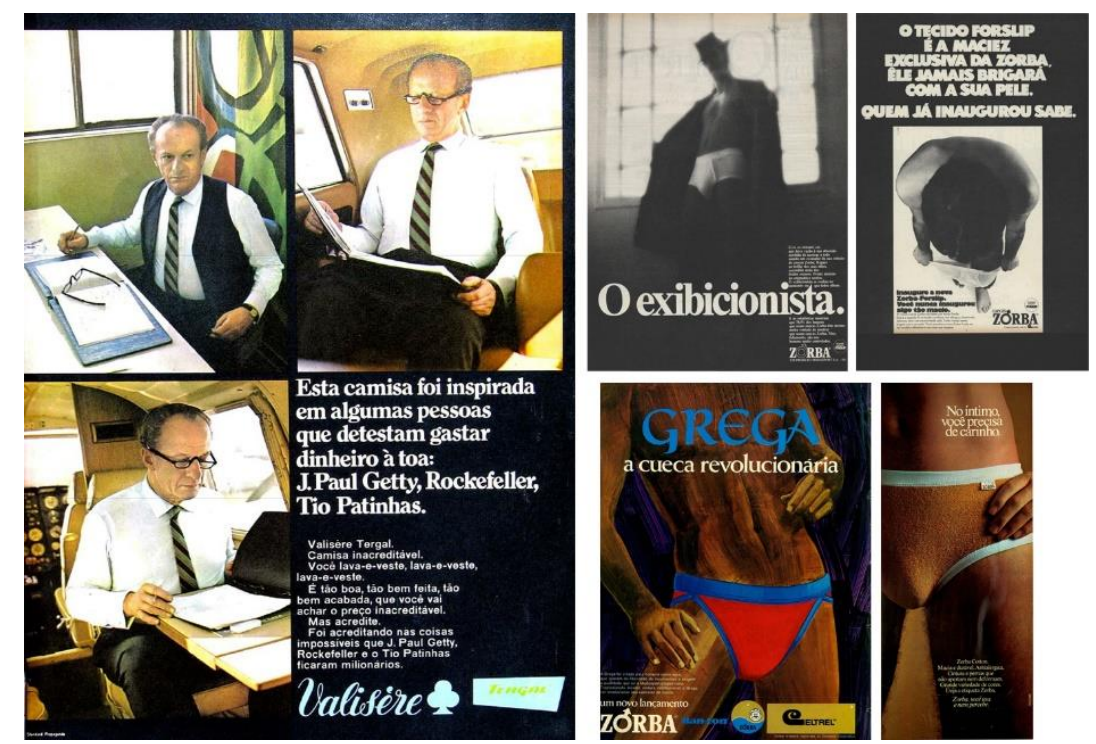

Figura 1: masculinidade hegemônica (esquerda) e outras masculinidades publicitárias (direita)

Na transição entre as décadas de 1990 e 2000, o campo publicitário se vale da asserção do "novo homem" para enfatizar, aguçar e potencializar o consumo das mercadorias que publicizavam. Autores como, Furtado (2008), Teixeira (2014) e Malacrida (2014) sinalizam como o ponta pé inicial desse fenômeno, o surgimento do metrossexual. Segundo esses autores, o aparecimento e a circulação do "novo homem" estavam atrelados à atualização em seus hábitos de consumo, principalmente, aqueles ligados à estética e cosmética. Outros pesquisadores, como Garcia (2005) e Garboggini (2005), ampliam essas discussões e asseveram que esse "novo homem" midiático e publicitário circulante, rompe em certos aspectos com a representação hegemônica de masculinidade. Para os autores, essa ruptura com a hegemônica, se deu pelas imagens de masculinidades da época, aparecerem, como ressalta Hoff (2008: 180), "fazendo compras, cuidando da casa e dos filhos, escolhendo roupas".

Contudo, Rosa (2008) e Bordinhão (2012) nos balizam com relação a um exacerbado entusiasmo acerca desse "novo homem", afinal para os autores esse homem assim como essas outras representações tomam como referencial a matriz imagética masculina hegemônica. Dessa forma, precisamos entender que essas outras masculinidades, algumas intituladas como novo homem, "atualiza[m] e flexibiliza[m] o padrão hegemônico que vigorou historicamente de forma bastante rígida" (BORDINHÃO, 2012: 129).

O entrave se instaura, quando essas atualizações da representação [midiática] da masculinidade hegemônica se deparam com alas mais conservadores da sociedade, elas veem que essa representação está mudando e o discurso publicitário, por ser um elemento social articulado em contextos socioculturais, também fornecem narrativas que ensejam a volta dos valores tradicionais de masculinidade. Um exemplo, hoje, são os comerciais da marca de desodorantes Old Spice, que valorizam "a ideia do orgulho de ser e cheirar a homem" (POSTINGUEL, 2015: 130).

Interessando-nos, problematizar a harmonização com relação à circulação de todas as masculinidades midiáticas. Dessa forma, no último ano, percebemos 
1 O GLOBO ONLINE. Drag queens e transexuais estrelam propaganda de marca de sorvetes. 2015. Disponível em: http://oglobo.globo.com/sociedade/drag -queens-transexuais-estrelampropaganda-de-marca-de-sorvetes16236082

2 EXAME.COM. Transgênero é protagonista de novo vídeo do Google. Disponível em:

http://exame.abril.com.br/marketing/no ticias/transgenero-e-protagonista-denovo-video-do-google

3 G1. Boticário mostra casais gays em comercial de Dia dos Namorados. 2015. Disponível em:

http://g1.globo.com/economia/midia-emarketing/noticia/2015/05/boticariomostra-casais-gays-em-comercial-de-diados-namorados.html que, além da circulação da masculinidade hegemônica, começaram a ter espaço midiático e publicitário aquelas representações sociais de masculinidade tidas como marginais. Três exemplos ilustram o que entendemos por masculinidades marginais, foram aquelas que circularam nos anúncios da marca de sorvetes Magnum $^{1}$, do Google My Business ${ }^{2}$ e no Dia dos Namorados para a linha Egeo, do O Boticário ${ }^{3}$ (nacional).
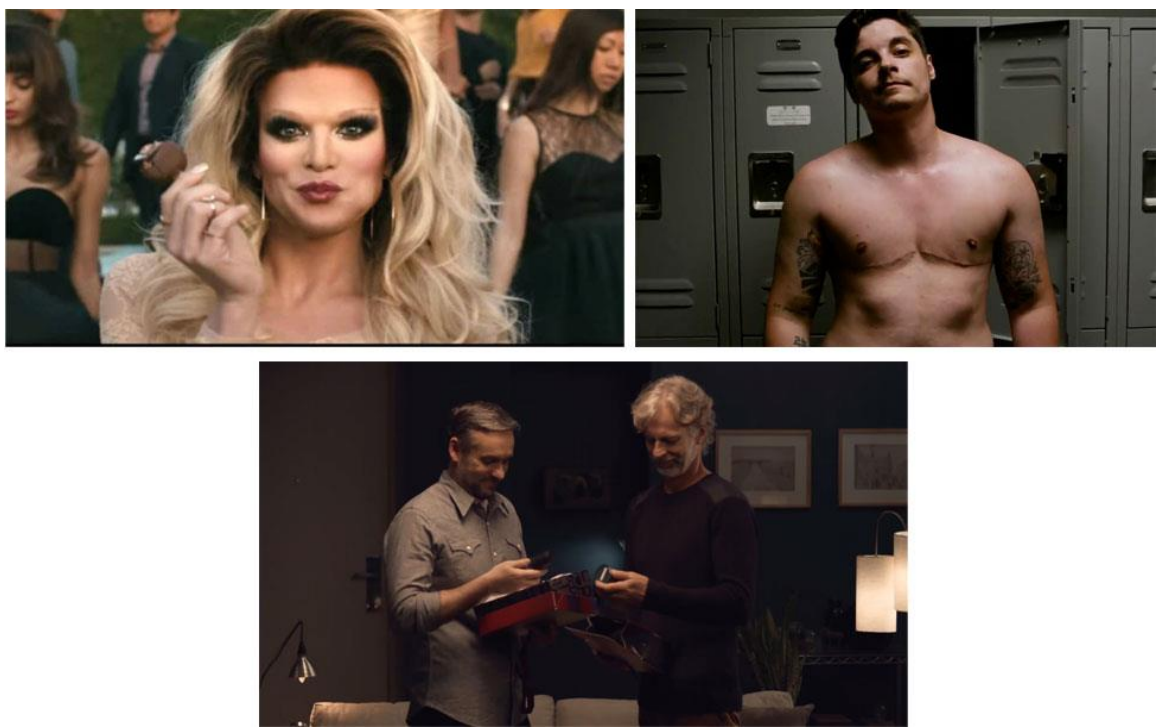

Figura 2: capturas dos anúncios Magnum, Google e O Boticário

Na Figura 2, na parte superior, emergem no campo publicitário representações, outrora circulantes apenas no plano social, que brincam com esse jogo entre o masculino e o feminino. Nas imagens captadas, vemos representações, do lado esquerdo, tipicamente feminina, protagonizadas no anúncio por drag queens e travestis. Referente ao lado direito, um homem transgênero. Ambas as representações, desde aquela que nega como aquela que busca por essa masculinidade, suscitam discussões as quais a antropologia há algum tempo tentar equacionar acerca do entendimento do que é biológico e o que é cultura na constituição identitária do indivíduo.

Outro anunciante que apresentou essas masculinidades marginais, antes não publicizadas massivamente, foi O Boticário. Num comercial da empresa (parte inferior) vemos um casal protagonizado por dois homens maduros, presente no mesmo plano midiático e social das demais representações, tradicionalmente hegemônicas. Complementar a isso, sinalizam que a homossexualidade não é algo restrito às experiências juvenis.

Para isso, Leite (2014), com a sua proposta de publicidade contra-intuitiva, reforça a necessidade da articulação da publicidade com os mais variados contextos socioculturais, trazendo em seus anúncios, discursos e imagens da atualidade. Para isso, define a ideia de publicidade contra-intuitiva, como:

[...] narrativa essa que propõe, mediante a sua mensagem, romper (deslocar) com a tradição dos estereótipos negativos aos quais determinados indivíduos estão inscritos de forma estigmatizada, operando nesse exercício um esforço para ressignificar o conteúdo desses estereótipos (LEITE, 2014: 23).

Assim, pensar nessa harmonização entre todas as masculinidades midiáticas, perpassa não só compreender a reprodução e ancoragem dessas masculinidades midiáticas na sociedade e no indivíduo, mas entender que são produções sociais e que a publicidade tem grande relevância nesse processo de criação e depois, aceitação social (CONNELL, 1995). Se outrora essas masculinidades eram construídas, exclusivamente, pelas instituições sociais e econômicas, agora são 
fornecidas, repensadas e atualizadas também, pelo campo comunicacional publicitário.

\section{Publicidade, espaço para investimentos... sociais}

Santos, no artigo, Para pensar a recepção publicitária: anotações empíricas sobre procedimentos metodológicos, discute sobre os estudos de recepção publicitária, e "a necessidade de aprimorarmos bases referenciais que viabilizem compreender a relação entre a publicidade e os receptores" (SANTOS, 2014: resumo). As reflexões do autor nos dão pistas na tentativa de solucionarmos a empreitada investigativa deste artigo.

Para isso, torna-se necessário e oportuno mobilizar esforços empíricos, teóricos e epistêmicos acerca da publicidade, para "que entenda a [sua] natureza multifacetada [...] e ultrapasse as questões puramente econômicas, considerando, sobretudo, o contexto da sociedade contemporânea" (SANTOS, 2014: 74). Além disso, os anúncios publicitários "como toda construção discursiva, produzem efeitos de verdade e alimentam a formação de subjetividades" (CARRASCOZA, 2012: 2).

Os dizeres publicitários tornam-se assim, um expoente objeto de estudo, "uma vez que retrata[m] e dissemina[m] os valores e as ideias vigentes dos períodos históricos da sociedade" (SANTOS, 2014: 77). Como também, permitem atualizar e repensar alguns valores por vezes cristalizados em determinados contextos socioculturais. Ao passo que, esse exercício de repensar as masculinidades imagéticas articuladas a seu tempo sócio-histórico, nos convoca "a dar visibilidade reflexiva às imagens da diferença, enfatizando a pluralidade das representações sociais correntes e a parcialidade mesma daquelas que se pretendem hegemônicas" (ROCHA, 2012: 38) dentro de um contexto cultural e seus desdobramentos.

Ao encontro disso, comungamos com as reflexões de Santos (2014), de fato, precisamos mobilizar esforços técnicos, teóricos e empíricos para compreender a comunicação e posterior recepção publicitária e como ela pode ensejar numa gama de imagens masculinas circulantes nesse espaço comunicacional, possibilitando mensurar como esses receptores recebem, decodificam e ressignificam esses anúncios. Afinal de contas, o atual momento político em nosso país se mostra frutífero para falarmos, repensarmos e problematizarmos as representações midiáticas circulantes e outrora, inexistentes, na publicidade. Para isso, reiteramos, precisamos reconhecer a publicidade como processo imerso em um contexto efetivamente cultural e de caráter interdisciplinar, pois,

(...) no campo da Comunicação, em particular, e das Ciências Sociais, em geral, a publicidade deveria aparecer como tema de interesse central para pesquisadores, pois estudar imagens, valores e ideologias que essas mensagens expressam, ocupando espaços urbanos, páginas de revistas e jornais se misturando às produções de rádio, televisão e cinema, é buscar conhecer valores, conceitos, modelos de ser, agir e se relacionar na sociedade contemporânea (ROCHA em prefácio de GASTALDO, 2013: 11).

Reforçamos ainda que, a publicidade além de ser "um registro eloquente da experiência social contemporânea [...] ensina modos de sociabilidade enquanto explica o quê, onde, quando e como consumir" (ROCHA, 2006: 11); enxergando aquilo que Hoff (2008) chamou de pedagogização do consumo. Partilhamos da afirmação de Rocha, pois a publicidade oferta o consumo de mercadorias, mas também, possibilita modos de sociabilidade, por meio do consumo de seus anúncios, não só projetando estilos de vida e fomentando referenciais identitários. Para isso, oferta nessas imagens, maneiras de conhecermos a nossa 
própria sociedade, principalmente no que se refere ao processo de atualização da mesma. Reproduzindo e/ou dando novos sentidos à narrativa publicitária disponível.

Com relação aos sentidos, eles são "construído[s] pelo receptor a partir de um conjunto diário e contínuo de publicidades recebidas" (SANTOS, 2014: 84). Neste percurso, a comunicação publicitária, nos últimos anos tem promovido "deslocamentos significativos nos regimes de visibilidade" (HOFF, 2012: 153), o que possibilita produzir e oferecer diferentes (e divergentes) imagens de masculinidades. Essas imagens ao passo que geram uma visão múltipla e variada do mundo, em contrapartida, desestabilizam, promovem tensão e uma possível ruptura com as imagens cristalizadas e hegemônicas. Esse é o atual embate teórico, político e social que estamos atravessando, devido à quantidade de anúncios publicitários que trazem representações atípicas de masculinidade para uma comunicação publicitária massiva.

Tensionando a aparição midiática de todas essas masculinidades que fogem (em maior ou menor intensidade) do modelo tradicional e que estão atravessando fluxos culturais por meio da narrativa publicitária, precisamos repensar se "o discurso publicitário só vai fazer referências [daqui para frente], portanto, ao que já está dado e é hegemonicamente consensual no contexto do 'público-alvo'" (GASTALDO, 2013: 23) ou promoverá a infinidade de representações sociais que existem em nosso contexto sócio-histórico-cultural.

Nesta empreitada, mesmo tendo consciência das investidas financeiras por traz dessas campanhas, algumas marcas assumem esse papel de promotoras de outras representações, que trilham caminhos opostos e se chocam com alguns desses valores e representações tradicionais e hegemônicos, cumprindo um papel importante na desmistificação de um ideal masculino e igualdade social.

Outra questão a ser pontuada neste estudo, é a razão da recorrência da publicidade em criar nos anúncios um espaço propício para a interação social. Eles criam lugares de encontro, emoldurando "um amplo conjunto de relações sociais" (ROCHA, 2006: 18), como também de representações midiáticas, ao passo que promovem essas interações, apresentam formas de convivência e sociabilidade. Por sua vez, esses modos de se ofertar sociabilidades, principalmente com relação à circulação das várias formas imagéticas de masculinidades podem se tornar um potencial ferramental para a conscientização de uma sociedade que é heterogênea. Sociedade essa versada em multiplicidades e particularidades onde o igual, mas também o diferente, tenham espaço de visibilidade e respeito, como de diálogo.

Assim, discutir a circulação, harmonização e sociabilidade de todas as masculinidades imagéticas na comunicação publicitária, "nos permite refletir sobre as fronteiras entre o social, o midiático e as práticas de consumo, pois [...] evidencia como os mercados [podem estar] sensíveis ao tema e o materializam [em seus anúncios]" (HOFF, 2012: 148). Sendo assim, esta pesquisa assumidamente tímida, mas inicial, além de problematizar a harmonização de múltiplas imagens de masculinidade na comunicação publicitária, provoca como desdobramento a urgência e a relevância de pesquisas, como articula Rocha (2008), sinérgicas com a realidade nacional, mas sensível a fluxos de maior abrangência internacionais.

\section{Considerações finais}

Na empreitada de compreendermos a possibilidade de circulação e posterior harmonização de todas as masculinidades possíveis na comunicação publicitária, 
entendemos de início que algumas estratégias são fundamentais para tal propósito. A primeira delas é compreender o consumo como um aliado desse processo, ao considerá-lo um fato da cultura. Afinal, incessantemente consumismos imagens para compreender a nossa realidade e nos constituirmos como indivíduos.

Articulamos a isso, o papel da comunicação publicitária que, de início, ao permitir colocar em circulação massiva outras imagens de masculinidades - não se restringindo à hegemônica -, além de sinalizar interesse com as demandas dos contextos socioculturais na qual está inserida, pode, naquilo que Hoff nomeou como pedagogização do consumo, não só ofertar formas de se consumir as mercadorias contidas no anúncio publicitário. Mas também, formas de construir uma sociabilidade dessas várias representações imagéticas de masculinidades. Principalmente no que tange as representações masculinas ainda hoje marginalizadas em nossa sociedade.

Além disso, para que essas emergentes masculinidades imagéticas sejam aceitas coletivamente e convivam com a hegemônica, torna-se necessário para a sociedade acadêmica suscitar uma memória coletiva dessas imagens outrora veiculadas no discurso publicitário (Figura 1), para que, a sociedade civil e o campo prático compreendam não como um processo atual e abrupto (Figura 2). Mas que vem gradativamente sendo gestado e ofertado.

Por fim, repensar o papel da comunicação publicitária, na criação, circulação e harmonização de todas as possíveis representações imagéticas masculinidades, tensionando a isso, o fluxos culturais, assim como, a publicidade global e a isso, os desdobramentos em nossa sociedade e comunicação.

\section{Referências}

BORDINHÃO, F. Identidade de gênero: anotações sobre a masculinidade contemporânea na publicidade. Cadernos de Comunicação, Santa Maria, v. 16, n. 1, jan/jun. p. 1-15. 2012. Disponível em: <http://cascavel.ufsm.br/revistas/ojs2.2.2/index.php/ccomunicacao/article/view/5839/4333>.

CASAQUI, V. Por uma teoria da publicização: transformações no processo publicitário. Significação: Revista de Cultura Audiovisual, São Paulo, v. 38, n. 36. p. 131-151. 2011. Disponível em: <http://www.revistas.usp.br/significacao/ article/view/70935/73840>.

CONNELL, R. W. Políticas da masculinidade. Educação \& Realidade, Porto Alegre, v. 20, n. 2, p. 185-206, jul./dez. 1995.

CONNELL, R. W.; MESSERCHMIDT, J. W. Masculinidade hegemônica: repensando o conceito. 'Estudos Feministas, Florianópolis, v. 21, n. 1 p. 241-282, jan./abr. 2013. Disponível em: <https://periodicos.ufsc.br/index.php/ref/article/view/ S0104-026X2013000100014/24650>.

CARRASCOZA, J. A. Memória oficial e subterrânea em filmes publicitários de marcas absolutas. In: CONGRESSO BRASILEIRO DE CIÊNCIAS DA COMUNICAÇÃO Intercom, 35., 2012, Fortaleza. Anais eletrônicos... Fortaleza: Unifor, 2012. Disponível em: <http://www.intercom.org.br/papers/nacionais/2012/resumos/ R7-2036-1.pdf >.

FURTADO, J. A. Porque eu sou é homem: a representação do masculino na publicidade brasileira na década de 1970 e nos anos 2000. 2008. Dissertação 
(Mestrado em Comunicação e Práticas de Consumo) - Escola Superior de Propaganda e Marketing, São Paulo, 2008.

GARBOGGINI, F. B. O homem na publicidade da última década. Uma cultura em mutação? Educar em Revista, Curitiba, n. 26, p. 99-114, 2005. Disponível em: $<$ http://www.scielo.br/pdf/er/n26/n26a08.pdf>.

GARCIA, W. Corpo, mídia e representação: estudos contemporâneos. São Paulo: Pioneira Thomson Learning, 2005.

GASTALDO, E. Publicidade e sociedade: uma perspectiva antropológica. Porto Alegre: Sulina, 2013.

HOFF, T. Notas sobre consumo e mercado no Brasil a partir das representações de corpo na publicidade. In: BACCEGA, M. A. (org.). Comunicação e culturas do consumo. São Paulo: Atlas, 2008.

Produção de sentido e publicização do discurso da diferença na esfera do consumo. In: ROCHA, R. M.; CASAQUI, V. Estéticas midiáticas e narrativas do consumo. Porto Alegre: Sulina, 2012.

LEITE, F. Publicidade contraintuitiva: inovação no uso de estereótipos na comunicação. Curitiba: Appris, 2014.

MALACRIDA, R. O novo homem na publicidade: consumindo e protagonizando anúncios publicitários. In: CONGRESSO BRASILEIRO DE CIÊNCIAS DA COMUNICAÇÃO - Intercom, 37., 2014, Foz do Iguaçu. Anais eletrônicos... Foz do Iguaçu: Unicentro, 2014. Disponível em: <http://www.intercom.org.br/papers/ nacionais/2014/resumos/R9-1671-1.pdf>.

NOLASCO, S. O mito da masculinidade. Rio de Janeiro: Rocco, 1993.

OLIVEIRA, P. P. A construção social da masculinidade. Belo Horizonte: Editora UFMG; Rio de Janeiro: IUPERJ, 2004.

PIEDRAS, E. R. Publicidade, imaginário e consumo: anúncios no cotidiano feminino. E-compós, Brasília, v. 11, n. 3, p. 1-17, set./dez. 2008. Disponível em: $<$ http://www.compos.

org.br/seer/index.php/e-compos/article/view/306/299>.

POSTINGUEL, D. Homem homem, homem com $H$ e homem-imagem: masculinidades midiáticas nas culturas do consumo. 2015. Dissertação (Mestrado em Comunicação e Práticas de Consumo) - Escola Superior de Propaganda e Marketing, São Paulo, 2015.

RIBEIRO, C. R. S.; SIQUEIRA, V. H. F. Construindo a masculinidade hegemônica: acomodações e resistências a partir da apropriação de personagens de novelas por adolescentes das camadas populares. In: REUNIÃO ANUAL DA ANPED, 28., 2005, Caxambu. Anais eletrônicos... Caxambu: 2005. Disponível em: <http://www.anped.org.br/reunioes/28/textos/ge23/ge231250int.rtf>.

ROCHA, E. Representações do consumo: estudos sobre a narrativa publicitária. Rio de Janeiro: Ed. PUC-Rio: Mauad, 2006.

ROCHA, R. M. É a partir de imagens que falamos de consumo: reflexões sobre fluxos visuais e comunicação midiática. In: BACCEGA, M. A.; CASTRO, G. G. S. (orgs.). Comunicação e consumo nas culturas locais e global. São Paulo: ESPM, 2009. 
A pureza impossível: consumindo imagens, imaginando o consumo. In: ROCHA, R. M.; CASAQUI, V. (orgs.). Estéticas midiáticas e narrativas do consumo. Porto Alegre: Sulina, 2012.

ROSA, E. Porque o homem não muda. Evolui. Um estudo sobre a relação entre masculinidade, paternidade e publicidade na sociedade contemporânea. In: SEMINÁRIO INTERNACIONAL FAZENDO GÊNERO, 8., 2008, Florianópolis. Anais eletrônicos... Florianópolis: UFSC, 2008. Disponível em: <http://www .fazendogenero.ufsc.br/8/sts/ST21/Elisabeth_Rosa_21.pdf>.

SANTOS, F. B. Masculinidade em anúncio(s): recepção publicitária e identidade de gênero. 2012. Dissertação (Mestrado em Comunicação) - Universidade Federal de Santa Maria, Santa Maria, 2012.

SANTOS, F. B.; RONSINI, V. M. Masculinidade e publicidade: a mediação da socialidade a partir das questões de classe. In: CONGRESSO BRASILEIRO DE CIÊNCIAS DA COMUNICAÇÃO - Intercom, 35., 2012, Fortaleza. Anais eletrônicos... Fortaleza: Unifor, 2012. Disponível em: <http://www.intercom.org.br/papers/ nacionais/2012/resumos/R7-2345-1.pdf >.

SANTOS, F. B. Para pensar a recepção publicitária: anotações empíricas sobre procedimentos metodológicos. Animus, Santa Maria, v. 13, n. 25. p. 71-87. 2014. Disponível em: <http://cascavel.cpd.ufsm.br/revistas/ojs-2.2.2/index.php/ animus/article/view/15774/pdf>.

TEIXEIRA, N. C. R. B. Gênero e mídia na Revista O Cruzeiro: gestando a metrossexualidade. In: CONGRESSO BRASILEIRO DE CIÊNCIAS DA COMUNICAÇÃO - Intercom, 37., 2014, Foz do Iguaçu. Anais eletrônicos... Foz do Iguaçu: Unicentro, 2014. Disponível em: <http://www.intercom.org.br/papers/ nacionais/2014/resumos/R9-1550-1.pdf>.

WOODWARD, K. Identidade e Diferença: uma introdução teórica e conceitual. In: SILVA, T. T. (org). Identidade e diferença: a perspectiva dos estudos culturais. Petrópolis: Vozes, 2009. 